\title{
Reversible and Non lethal Weapons: A path to disarmament.
}

Dr Bheemaiah, Anil Kumar, World Peace Resonance, A.B, Seattle WA 98125, USA.

miyawaki@yopmail.com

\section{Abstract:}

High casualty figures of innocent citizens in a conflict, proven internal and projected in political thinking and boundaries on neighbouring nations are often higher than insurgent threats, yet when war is inevitable, and armament needed to maintain a political identity, there is a need for a new paradigm, that of Peace Weapons $\left({ }^{\mathrm{TM}}\right)$. Peace Weapons $\left(^{\mathrm{TM}}\right)$ make conflicts reversible and non-lethal in armament and directed weaponry, in this paper we illustrate the armament with a design of a light pollution map based automated drone bomber, with the replacement of conventional payload with sleep weapons, EMI weapons of Alpha/Beta and Delta/Gamma, deep sleep inducers. We prove that this EMI weapon is reversible in civilian casualty and can be selectively reversed after the conflict is resolved.

Keywords: EMI Weapons, Peace Weapons, Reversibility, Non- Lethal Weapons, Peace Movement, Disarmament, Sleep Inducing EMI Weapons.

\section{What:}

There is an increased Delta and Theta wave intensity in deep NREM sleep.

An EMI weapon can be created with an ability to induce these waves in a local or global area. A scalable drone solution exists with a payload of this EMI weapon.

The deep sleep is reversible selectively as biometrics in 5G LTE using WiFi as a radar can identify civilian subjects in deep sleep for reversing the weapons effect after the conflict ends.

Why:

Casualty of innocent civilians in internal and external conflicts has a toll of 20,000 lives each year in the United States alone. Lethal Weapons and road casualties exceed these figures. Drone Bombing, the future of conflict has been criticized for causing civilian casualties and 
hence having a poor impact. Consequently, is the need to replace all lethal weapons with reversible and non lethal weaponry called Peace Weapons $\left({ }^{\mathrm{TM}}\right)$.

Development is seen as an act of internal conflict leading to the creation of political systems and boundaries and the self destruction of the developed world in external conflict. All actors of development, including that of roads, inroads and urban and industrial infrastructure are seen as an internal conflict by innocent civilians, with a casualty in road mortality and domestic violence related to lethal weapons as the toll.

The indifference of administrations to the adoption of peaceful solutions like auto-pilot systems and drones to completely eliminate road casualties and the replacement of all lethal weapons with dual setting non lethal weapons, proves the nature of the internal conflict.

The abundance of entertainment and consumerist violence based scenarios, franchises and technology proves the inner nature of the psyche of the urban mindset, even amongst civilians. Hence this strain of the urban psyche is proven to be barbaric in nature needing casualty and conflict, both internal and external,

A Peace Movement is hence called for with a technological solution, autonomous navigation for all mobility, use of scalable drones and replacement of lethal weaponry with reversibility and non - lethality. Killing and bloodshed is not passe and not spiritually uplifting.

The spirituality of a "Good Day To Die", as popularized in the Klingon religion(Insight Editions 2017) is extinct.

Only such warriors may die in a false glory, leaving the Civilians to lead a life of peace.

\section{How:}

Light enough EMI weapons for drone payloads need to be developed, that can induce the required deep sleep waves.

The present generation of drone technology is sufficient to deploy payload at a local area or wide area target, with a higher impact factor than a TNT based disruption index.

\section{Introduction.}

\section{Synthetic Sleep and Stupor induction FDA approved technology.}

The nature of deep sleep in EEG Power Spectral Densities.

Sleep has been defined to have three phases in non REM sleep or NREM
sleep(Alam 2013; Szymusiak 2017), this deep sleep state is called Delta Sleep, characterized by a high ratio of Delta waves. The same sleep can be induced using a EMI wave generator and several FDA approved devices for sleep induction by delta waves are available in the market today. They are contact PEMF or near field devices.(Hug and Röösli 2012; MSc and Layne 2017; Valone 2003; Rosch and 
Markov 2004) Scaling to longer range devices is a topic of future research.

("Website" n.d., "Website" n.d.) SPECTRAL ANALYSIS OF HUMAN SLEEP

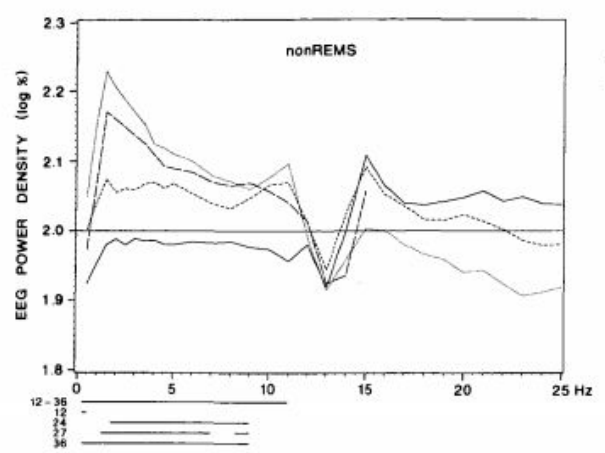

Stupor induction is an active area of research, with induced sleep lasting 8 to 12 hours, giving enough time for a ground based biometric filtering of subjects and in the case of medical use sufficient polyphasic and monophasic sleep. Prolonged stupor for space based synthetic stupor with altered thermoregulation is a topic of a separate publication.(Bagley 2006; Posner et al. 2019; Young 2014)

\section{Is an EMI weapon feasible using} Tesla's inventions to induce such waves over local and wide areas?

In counter Insurgency measures, often Peripheral Intrusion Detection (PID) systems(M. 2011; Morel 2011) can be created with dual use technology, like DAS systems coupled with a carrier based deep sleep technology.(Taheri and Nosrati 2014) The same delta wave sleep induction, much like the design of a transformer, can easily be created with Tesla technology(Valone 2003), with $5 \mathrm{G}$ biometric for drone payloads. This can be scaled from local area application to wide area application, particularly for PID end uses.
Once the entire population involved in an intrusion is slept, they can be reversibly woken up for investigation on their insurgent or civilian identities, thus implementing effective counter insurgency in a reversible and non-lethal manner. This is the return of Humane-Technology.

\section{Wide area and local area WiFi} proves EMI reception as a viable use in $5 G$ based biometrics.

High frequency RF in the mid to higher microwave range can be used in passive RF radars for human biometrics, to supplement Distributed Acoustic Systems (DAS) systems. Thus selective filters for delta sleep initiation also exist for precision strike capabilities.

\section{Sleep Induction as a Peace Weapon ${ }^{\mathrm{TM}}$ ).}

Sleep Induction technology is a Peace Weapon $\left({ }^{\mathrm{TM}}\right)$ as it is reversible and non-lethal, as once slept, the effect is reversible on a subject, with biometric filters, it is possible to non-invasively differentiate between innocent civilians and the target POWs. Thus it is possible to effectively disarm insurgents at the periphery, without violence, eliminating civilian casualties. 


\section{Conclusions and Future Work.}

In conclusion, we have described a road map to reversible and non-lethal technology, with a dual use PEMF based delta sleep induction, both for FDA approved cure for insomnia and for applications in counter insurgency and drone payloads.

Future work will investigate the use of Biometric 5G LTE to induce deep sleep by induction of delta waves, similar to PEMF technology. It has a dual use in treating insomnia.

\section{References.}

Alam, N. 2013. "NREM Sleep: Anatomy and Physiology." Encyclopedia of Sleep. https://doi.org/10.1016/b978-0-12-3786 10-4.00098-x.

Bagley, R. 2006. "The Cat with Stupor or Coma." Problem-Based Feline Medicine. https://doi.org/10.1016/b978-0-7020-24 88-7.50042-9.

Hug, Kerstin, and Martin Röösli. 2012. "Therapeutic Effects of Whole-Body Devices Applying Pulsed Electromagnetic Fields (PEMF): A Systematic Literature Review." Bioelectromagnetics. https://doi.org/10.1002/bem.20703. Insight Editions. 2017. Hidden Universe Travel Guides: Star Trek: The Klingon Empire. Simon and Schuster.

M., Khattab. 2011. "Intrusion Detection System and Artificial Intelligent." Intrusion Detection Systems. https://doi.org/10.5772/15271.

Morel, Benot. 2011. "Anomaly Based Intrusion Detection and Artificial
Intelligence." Intrusion Detection

Systems.

https://doi.org/10.5772/14103.

MSc, William Pawluk Md, and Caitlin Layne. 2017. Power Tools for Health: How Pulsed Magnetic Fields (PEMFs) Help You. FriesenPress.

Posner, Jerome B., Clifford B. Saper, Nicholas D. Schiff, and Jan Claassen. 2019. "Structural Causes of Stupor and Coma." Plum and Posner's Diagnosis and Treatment of Stupor and Coma. https://doi.org/10.1093/med/978019020 8875.003.0003.

Rosch, Paul J., and Marko S. Markov. 2004. Bioelectromagnetic Medicine. CRC Press.

Szymusiak, Ronald. 2017. "Neurobiology of NREM Sleep and Thermoregulation in Sleep." Sleep Disorders Medicine. https://doi.org/10.1007/978-1-4939-657 8-6 8.

Taheri, Sayed Mostafa, and Hamed Nosrati. 2014. "Acoustic Signature Identification Using Distributed Diffusion Adaptive Networks." 2014 9th International Symposium on Communication Systems, Networks \& Digital Sign (CSNDSP).

https://doi.org/10.1109/csndsp.2014.69 23965.

Valone, Thomas. 2003. Bioelectromagnetic Healing: A Rationale for Its Use. Integrity Research Inst.

"Website." n.d. Accessed August 22, 2019a. https://academic.oup.com > sleep > article-pdf. - n.d. Accessed August 22, 2019b. 1: Christensen JA, Munk EG, Peppard $P E$, Young $T$, Mignot $E$, Sorensen $H B$, Jennum $P$. The diagnostic value of power spectra analysis of the sleep electroencephalography in narcoleptic patients. Sleep Med. 2015 Dec;16(12):1516-27. doi: 10.1016/j.sleep.2015.09.005. Epub 2015 Sep 15. PubMed PMID: 26611950.https://academic.oup.com > 
sleep > article-pdf.

Young, G. B. 2014. "Stupor." Encyclopedia of the Neurological Sciences.

https://doi.org/10.1016/b978-0-12-3851

57-4.00344-4. 